\title{
Cari İşlemler Dengesi ve Ekonomik Büyüme Arasındaki İlişki: Tacikistan Cumhuriyeti Örneği
}

\section{Relationship Between Current Account Balance and Economic Growth: Example of the Republic of Tajikistan}

\author{
Hakan Acet $^{1 *(D)} \quad$ Emomjafar Ashurov ${ }^{2}$ (D) \\ ${ }^{1}$ Department of Economics, Selçuk University, Konya, Turkey \\ ${ }^{2}$ Insititute of Social Sciences, Departament of Ekonomics, PhD student, Selcuk University, Konya, Turkey
}

\begin{abstract}
Received: 20.07 .2020
Accepted: 09.09.2020

This article was checked by intihal.net

ISSN: $2149-8598$

Öz

Cari işlemler açığı, birçok gelişmiş ve gelişmekte olan ülkelerde olduğu gibi Tacikistan ekonomisi için de önemli bir makroekonomik sorundur. Literatürde bu konu hakkında yapılan çok sayıda analizlere rağmen Tacikistan ekonomisi üzerine yapılan Literatür incelendiğinde yapılan çalışmalar sadece teorik düzeyde kalmaktadır. Tacikistan ekonomisinde 2005 yılından bu yana yüksek cari açık yaşanmaktadır. Dolayısıyla bu çalışmanın amacı cari açık, ekonomik büyüme arasındaki ilişkiyi ampirik analizle ortaya koyarak literatüre katkı sağlanmaktır. Bu amacı gerçekleştirmek için cari işlemler dengesi (CID) ve ekonomik büyüme (GSYH) \%'sel olarak alınmıştır. Yapılan analizde 2005Q1-2019Q4 çeyrek veriler kullanılmaktadır. Veriler Dünya Bankası ve Tacikistan Cumhuriyeti Merkez Bankası'ndan alınmıştır. İlk değişkenlerimizin durağan olup olmadığını belirlemek amacıyla birim kök testi uygulanmıştır. Analiz sonucuna göre; bir değişken birinci farkta durağanken diğeri ise düzeyde durağındır. Bu nedenle analiz için ARDL modeli daha uygun görülmüştür. Değişkenler arasında ilişkiyi belirtmek için Kovaryans testi uygulanmıştır. Elde edilen ampirik bulgulara göre değişkenler arasında negatif bir ilişki bulunmaktadır. Aynı zamanda ARDL sınır test sonuçlarına göre değişkenler arasında uzun dönem bir ilişki vardır. Bunun dışında bu çalışmada Korelogram, Histogram normallik testi ve ARCH gibi testler de uygulanmıştır.
\end{abstract}

Anahtar Kelimeler: ARDL modeli, CID, GSYH, Tacikistan, Dünya Bankası

\begin{abstract}
The current account deficit is a major macroeconomic problem for the economy of Tajikistan, as in many developed and developing countries. Despite numerous analyses on this subject in the literature, studies on the economy of Tajikistan remain only at the theoretical level. Tajikistan's economy has experienced a high current account deficit since 2005. Therefore, the aim of this study is to contribute to the literature by revealing the relationship between current account deficit and economic growth through empirical analysis. To achieve this goal, the current account balance (CID) and economic growth (GDP) were taken as\%. 2005q1-2019q4 quarter data are used in the analysis. Quarter data is taken from the World Bank and the Central Bank of the Republic of Tajikistan. A unit root test was performed to indicate whether our first variables are stationary. According to the analysis result, one variable is stationary in the first difference, and the other is stationary at the level. For this reason, the ARDL model was considered more suitable for analysis. Covariance testing was applied to indicate the relationship between variables. According to the empirical results obtained, there is a negative relationship between the variables. At the same time, there is a long-term relationship between variables based on ARDL boundary test results. In addition, tests such as Korelogram, Histogram normality test and ARCH were also applied in this study.
\end{abstract}

Keywords: ARDL model, CAB, GDP, Tajikistan, World Bank.

Acet, H. \& Ashurov, E. (2020). "Cari İşlemler Dengesi ve Ekonomik Büyüme Arasındaki İlişki: Tacikistan Cumhuriyeti Örneği”, Journal of Academic Value Studies, 6(3) 266-279 (http://dx.doi.org/10.29228/javs.45418).

\footnotetext{
*Email address: hakanacet@selcuk.edu.tr (Corresponding author)
} 


\section{Giriş}

Cari işlemler dengesi ekonomilerin hassas ve önemli bileşenlerinden biri olarak kabul edilmektedir. Cari açık, bir ülkenin hükümetlerinin, işletmelerinin ve bireylerinin ihracatından daha fazla mal hizmet ve sermaye ithal etmesidir. Gelişmekte olan ülkelerin çoğu, üretimde yüksek düzeyde ithalat girdisi kullandıkları için cari işlemler açı̆̆ ile karşı karşıya kalmaktadır; ya da farklı bir şekilde ifade etmek gerekirse, büyümeleri ithalat odaklı büyümedir. Bununla birlikte, büyüme oranı ile cari işlemler açığı arasındaki bu ilişki her zaman doğru değildir. Özellikle ekonomik büyümenin dış ticaret fazlası ile gerçekleştiği ülkelerde reel milli gelirdeki reel artışlar cari açıkta iyileşmeye yol açabilir (Telatar O. M., 2007: s. 14).

Büyüyen bir ülke ekonomisinde üretim maliyetlerinde düşüş ve azalan maliyetlerle ihracat oranı arttığında, bu durum cari açık üzerinde olumlu bir etkiye neden olacaktır. Ancak, ekonomik büyümenin cari işlemler açığ 1 üzerindeki etkisinin yönü, bir ülkenin gelir artışından tasarruf edilen ve harcanan miktara bağlıdır. Harcanan tutar kaydedilen tutardan yüksekse, cari açık artacaktır. İthal mallar bir yandan ihracat malları üretmek için hammadde, yarı mamul veya sermaye malları olarak kullanıldığından ve bu nedenle üretim artışına neden olan ithalata bağlı ekonomik büyüme, kaçınılmaz olarak ithalatı ve nihayetinde cari açı̆̆ı artıracaktır (Coşkun, 2010: s. 21-22).

Literatürde yapılan çok sayıda çalışma, ekonomik büyüme ile cari açı arasındaki ilişkiyi incelemektedir. Debelle ve Faruqee (1996), hızlı ekonomik büyüme gösteren ülkelerin yüksek oranda cari açı eğiliminde olduklarını gösterirken, Calderon, Chong ve Loazya (2000) ise kırk dört gelişmekte olan ülke üzerinde yaptıkları araştırmalarda GSYH büyüme oranındaki artışın cari açıkta artışa neden olduğunu bulmuşlardır. Kandil ve Greene (2002) tarafından Amerika Birleşik Devletleri üzerine yapılan bir çalışma, cari işlemler açığının uzun vadede reel GSYH'deki artışlarla ilişkili olduğunu ve bu korelasyonun ters ve anlamlı olduğunu göstermiştir.

Tacikistan dışa bağlı bir ülke olduğu için cari işlemler genelde açık vermektedir. Tacikistan Merkez Bankasının verilerine göre 2005-2018 yıllar arasında ülkede sadece bir defa cari işlemler \%2, 2 fazla verip 13 yıl boyunca ortalama yaklaşık \%11 açık verilmiştir. Cari açığın ana nedeni dış ticaretin açık vermesidir. 2018 yılında 1,073 milyon dolarlık mal ihraç ederken 3,150 milyon dolarlık mal ithal edilmiştir. Bu yılın sonunda dış ticaret 2,078 milyon dolar açık vermiştir ki bu GSYH'nin \%28 oluşturmaktadır.

Çalışma dört bölümden oluşmaktadır. Giriş bölümünden sonraki ikinci bölümde, Ödemeler bilançosu ve ekonomik büyüme arasındaki ilişki incelenen dönem kapsamında değerlendirilmektedir. Üçüncü bölümde Tacikistan'da cari işlemler ve ekonomik büyüme arasındaki ilişki ele alınmaktadır. Dördüncü bölümde ise çalışmada yapılan analiz hakkında bilgi bulunmaktadır. Sonuç, analiz sonuçlarının yorumlanmasını içermektedir ve bazı öneriler sunmaktadır.

\section{Cari İşlemler Hesabı ve Ekonomik Büyüme Teorik Çerçeve}

Bir ülkenin ödemeler bilançosu (dengesi), belirli bir zaman diliminde dış dünya ile olan tüm ekonomik işlemlerinin sistematik bir kaydıdır. Ülkenin dünyanın geri kalanıyla ekonomik ilişkilerinin niteliğinin ve boyutlarının istatistiksel bir kaydidır.

Bir ülkenin ödemeler bilançosu kayıt tekniği çift kayıt muhasebe sistemine dayanmaktadır. Her işlem bilançonun kredi ve borç tarafına girilmektedir. Yani her uluslararası işlem, bir kez kredi tarafında ve bir kez borç tarafında, eşit miktarda iki kez kaydedilir. Bir ürün, bir ülkeye yabancılardan ödeme alma hakkı tanıyacağından, mal hesabının kredi tarafında (+) yer alacaktır. Ancak aynı zamanda, bu tutar ihracatçı ülkeden kısa vadeli sermaye çıkışını temsil ettiği için kısa vadeli sermaye borcu (-) olarak değerlendirilir (Aahana, 2020).

Cari işlemler dengesi, ödemeler bilançosunun en önemli bölümlerden biridir ve gerçek maddi değerlerin (mal ve hizmet) uluslararası hareketini gösterir.

Cari işlemler, mal ve hizmet ihracatının değeri ile mal ve hizmetlerin ithalat maliyeti arasındaki fark olarak ifade edilebilir. Cari işlemler aynı zamanda net geliri (faiz veya temettü gibi) ve genellikle toplamın küçük bir kısmını oluşturan yurtdışından (dış yardım gibi) transferleri de içermektedir. Cari işlemler aynı zamanda, ulusal (hem kamu hem de özel) tasarruf ve yatırım arasındaki fark olarak da ifade edilebilir. Bu nedenle bir cari açık, yatırıma göre düşük bir ulusal tasarruf seviyesini veya yüksek bir yatırım oranını veya her ikisini de yansıtabilir. Tasarrufları ulusal yatırımlardan daha fazla olan bir 
ülke, fazla tasarruflarını yurt dışına göndermektedir. Tasarrufları ulusal yatırımdan daha az olan bir ülke ise, fon eksikliğini yabancı yatırımlarla telafi etmektedir (Ghosh \& Ramakrishnan, 2020).

Yukarıda dediğimiz gibi cari işlemler, bir ülkenin ödemeler dengesinin bir parçası ve en önemli hesaptır. Cari işlemler dengesi bir ülkenin ticaret dengesi artı net gelir ve doğrudan ödemelerdir. Dolayısıyla cari işlemler hesabını oluşturan kalemlerinin açıklaması gerekmektedir. Tablo 2'de, ödemeler dengesi bileşenlerinin ayrıntılı bir açıklaması bulunmaktadır.

Tablo 1. Cari Işlemler Dengesinin Ana Kalemleri.

\section{CARİ İŞLEMLER DENGESİ}

\begin{tabular}{ll}
\hline A. & DIŞ TİCARET DENGESİ \\
\hline 1. & Genel Mal Ticareti (Ödemeler Dengesi Tanımlı) \\
\hline 1.1. & İhracat \\
\hline 1.2. & İthalat \\
\hline 2. & Net Transit Ticaret Geliri \\
\hline 3. & Parasal Olmayan Altın \\
\hline
\end{tabular}

\section{B. HIZZMETLER DENGESİ}

1. Başkasına ait Fiziksel Girdiler için İmalat Hizmetleri

2. Bakım ve Onarım Hizmetler

3. Taşımacilık

4. Seyahat

5. İnşaat

6. Sigorta ve Emeklilik Hizmetleri

7. $\quad$ Finansal Hizmetler

8. $\quad$ Fikri Mülkiyet Hakları Kullanım Ücretleri

9. Telekomünikasyon, Bilgisayar ve Bilgi Hizmetler

$10 . \quad$ Diğer İş Hizmetleri

11. Kişisel, Kültürel ve Eğlence Hizmetleri

12. Resmi Hizmetler

C. BİRINCİL GELİR DENGESI

1. Ücret Ödemeleri

$2 . \quad$ Yatırım Geliri

2.1. Doğrudan Yatırım

2.2. Portföy Yatırımları

2.3. Diğer Yatırımlar

D. İKINCİL GELİR DENGESI 
1. Genel Hükümet

2.

Diğer Sektörler

2.1 .

Kişisel Transferler

2.2 .

Diğer Transferler

Kaynak: (TCMB, 2020)

Eğer cari işlemler dengesini formül olarak yazmak istersek şöyle olacaktır.

$\mathrm{CID}=(\mathrm{X}-\mathrm{M})+(\mathrm{NY}+\mathrm{NKT})$

Burada:

$\mathrm{X}=$ Mal ve hizmet ihracatı

$\mathrm{M}=$ Mal ve hizmet ithalatı

NY = Yurtdışındaki net gelir

NCT $=$ Net akım transferleri

Bu formül cari hesabın açık veya fazla olup olmadığını belirttirmektedir. Aynı zamanda bu herhangi bir tutarsılı̆ğın nereden kaynaklanabileceğini ve daha iyi işleyen bir ekonomi sağlamak için kaynakların nasıl yeniden yapılandırılabileceği hakkında ülkelere yardımcı olacaktır (Heakal, 2019).

Ekonomik büyüme ise, bir ülke ekonomisinin zaman içinde ürettiği mal ve hizmetlerin piyasa değerindeki artıştır. Büyüme kavramı ülkenin tüm ekonomik çıktısını dikkate almaktadır ve ülkedeki işletmelerin satış için ürettiği tüm mal ve hizmetleri içermektedir. Üretilen mal veya hizmetin yurt içinde mi yoksa yurt dışında mı satıldığı önemli değildir. Çoğu ülke her üç ayda bir ekonomik büyümeyi ölçmektedir. Geleneksel olarak GSYH ekonomik büyümeyi ölçmenin en iyi yoludur ve büyümenin en doğru ölçümü ise reel GSYH’dir. GSYH büyüme oranı reel GSYH kullanmaktadır (Kimberly, 2019).

Daha da önemlisi, GSYH'nin nüfusa oranının (kişi başına düşen GSYH) artmasıdır ki bu kişi başına düşen gelirdir. Kişi başına gelirdeki artış yoğun büyüme olarak adlandırılmaktadır. Sadece nüfus veya bölgedeki artışların neden olduğu GSYH büyümesine kapsamlı büyüme denir. Büyüme, enflasyonun üretilen malların fiyatı üzerindeki çarpıtıcı etkisini ortadan kaldırmak için genellikle reel olarak (yani enflasyona göre ayarlanmış terimler) hesaplanır (ScienceDaily, 2020).

\section{Tacikistan'da Cari İşlemler Dengesi ve Ekonomik Büyüme İlişkisi}

Orta Asya’nın tam merkezinde yer alan ve bölgenin tek Farsça konuşan ülkesi olan Tacikistan SSCB'nin dağılmasından sonra 1991'de bağımsızlı̆̆ını elde etmiştir. 1991 yılında Sovyetler Birliği'nin dağılmasından sonra onun yerinde Bağımsız Devletler Topluğu (BDT) kurulmuştur. Bağımsızlığın ardından Tacikistan'da 1992-1997 dönemi boyunca bir iç savaş yaşanmış ve Tacikistan ekonomisi tehdit altında kalmışıı. Tacikistan ekonomisinin asıl gelişimi böylece 1997 yılında iç savaşın bitimi ile mümkün hale gelmiştir. Olumlu dış çevre ve ülkenin başlıca ihracat kalemleri olan pamuk ve alüminyum fiyatlarında yükselişler ile 2000'den 2014'e kadar Tacikistan'ın ekonomisi yıllık ortalama yüzde 7,9 oranında bir büyümeye ulaşmıştır. Öte yandan, Rusya ve diğer ticaret ortaklarındaki hızlı büyüme Tacikistan'ın emek talebini artırmış; bu da göçmen işçi gelirlerinin ve ardından iç tüketimin artmasına neden olmuştur (Ershov \& Sadriddinov, 2016). Aşağıdaki tabloda Tacikistan ve diğer BDT makroekonomik göstergeleri bulunmaktadır.

Tablo 2. Bağımsız Devletler Topluluğu Ülkelerinin Genel Makro Ekonomik Göstergeleri (2018)

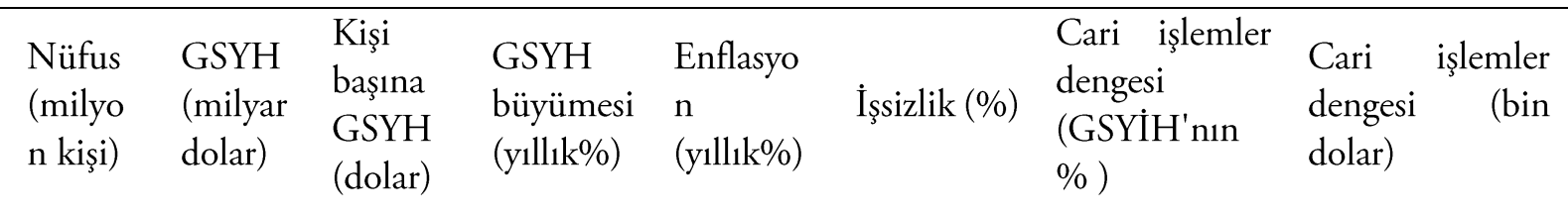




\begin{tabular}{|c|c|c|c|c|c|c|c|c|c|c|c|}
\hline Ermenistan & 9,2 & 12,4 & 421,1 & 2 & 5 & & 2,5 & 5 & 17 & $-9,4$ & $-1,165,3$ \\
\hline Azerbeycan & 9,9 & 46,9 & 4721,2 & 4 & 1 , & & 1,9 & & 4,9 & 12,9 & $6,051,0$ \\
\hline Beyaz Rusya & 9,5 & 59,6 & 6289,9 & & 3 & & 4,9 & & 4,8 & $-0,1$ & $-34,4$ \\
\hline Kazakistan & 18,2 & 173 & 9812,6 & 1 & 4 & & 6 & & 4,8 & $-0,2$ & $-288,8$ \\
\hline Kırgizistan & 6,3 & 8,1 & 1281,4 & 5 & 3 & & 1,5 & & 5,9 & $-8,9$ & $-718,4$ \\
\hline Moldova & 2,7 & 11,4 & 3227,3 & 4 & 3 & & 3 & & 2,9 & $-10,6$ & $-1,2114$ \\
\hline Rusya & 144,5 & $\begin{array}{l}1,657, \\
5\end{array}$ & $\begin{array}{l}11288, \\
9\end{array}$ & & 2,25 & & 2,9 & & 4,8 & 6,8 & $113,454,9$ \\
\hline Tacikistan & 9,2 & 7,5 & 826,6 & & 7,3 & & 6,7 & & 11,1 & -5 & $-378,4$ \\
\hline $\begin{array}{l}\text { Türkmenista } \\
\mathrm{n}\end{array}$ & 5,8 & 40,8 & 6966,6 & 6,2 & & 7,9 & & 3,8 & & - & - \\
\hline Ukrayna & 44,6 & 130,8 & 3095,2 & 3,3 & & 10,9 & & 8,8 & & $-3,3$ & $\begin{array}{c}- \\
43,670,0\end{array}$ \\
\hline Özbekistan & 32,9 & 50,5 & 1532,4 & 5,1 & & 4,3 & & 5,7 & & $-7,1$ & $\begin{array}{c}- \\
35,938,9\end{array}$ \\
\hline
\end{tabular}

\section{Kaynak: (Dünya Bankası, 2019)}

Tabloda görüldüğü üzere BDT ülkelerinde 2018 yılında sadece iki devlette cari işlemler fazlalığı vardır. Diğer bütün ülkelerde (Türkmenistan için veri bulamamıştık) cari işlemlerde bir açık vardır. Aşağıdaki grafikte ise 2005-2018 yılları arası Tacikistan'da cari işlemler dengesi ve ekonomik büyüme dağılımı verilmektedir.

Grafik 1. Cari Açık ve Ekonomik Büyüme hızı

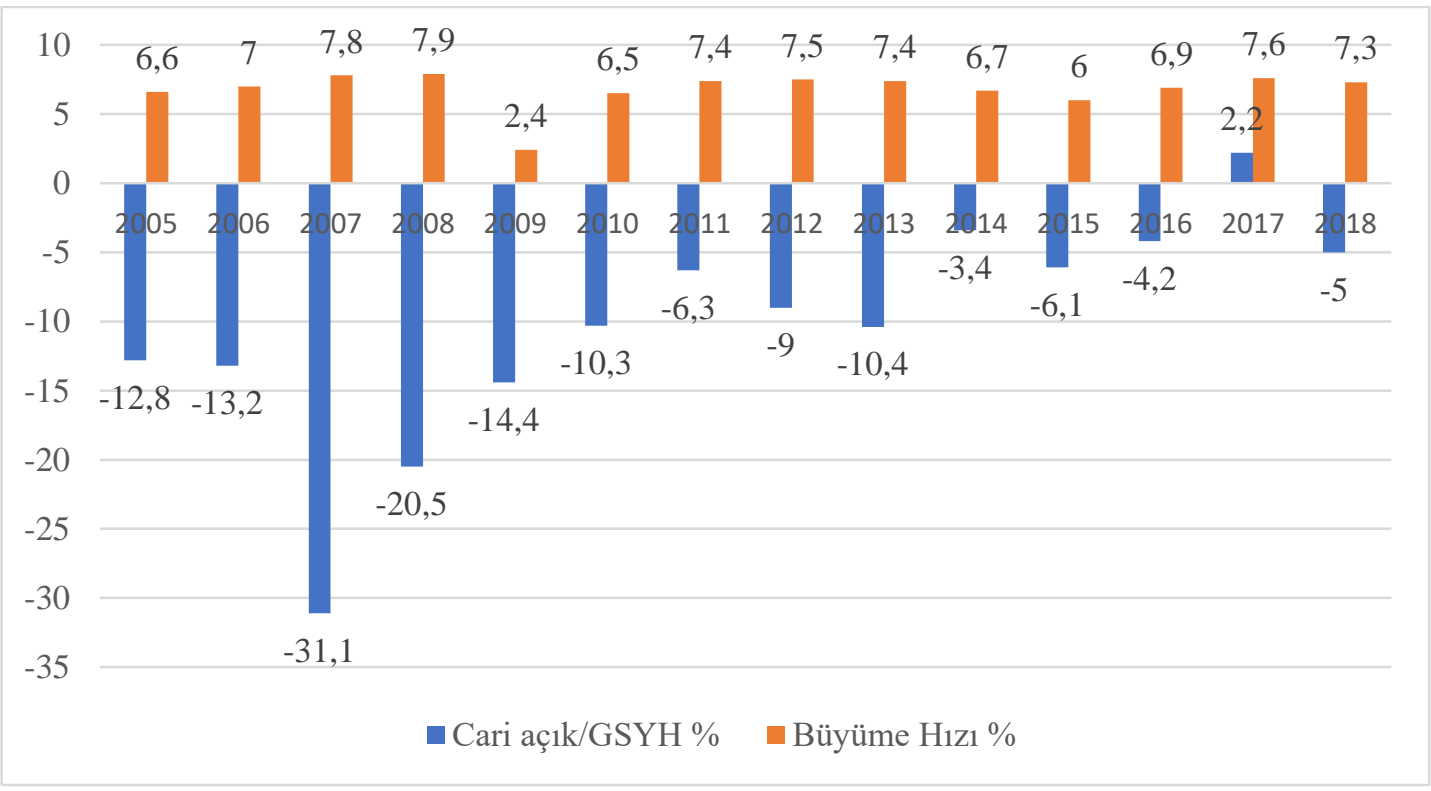

Kaynak: (The World Bank, 2020) 
Grafikte görüldüğü gibi 2005-2016 yıllar arasında cari işlemler dengesi her zaman açık vermiştir. Sadece 2017 yılında cari işlemler dengesi \%2,2 fazla vermiştir. 2018 ise yine cari işlemler dengesi \%5 açık vermiştir.

\section{Literatür Taraması}

Son yıllarda yapılan çalışmalarda DYY ile ekonomi büyüme arasındaki ilişki bazı çalışmalarda pozitifken, bazı çalışmalarda ilişki bulunmadığı sonucuna varılmıştır. Aşağıdaki tabloda DYY ile ekonomik büyümeye kapsayan yerli ve yabanci literatür verilmektedir.

Tablo 3. Konu Hakkında Yapılan Literatür Özeti

\begin{tabular}{|c|c|c|c|c|}
\hline Yazar (lar) & Metodoloji & Dönem & Ülke & Sonuçlar \\
\hline $\begin{array}{l}\text { (Telatar \& Terzi, } \\
\text { 2009) }\end{array}$ & $\begin{array}{l}\text { Granger } \\
\text { nedensellik, } \\
\text { VAR analizleri } \\
\end{array}$ & $1991: 4-2005: 4$ & Türkiye & $\begin{array}{l}\text { Büyüme oranı ve cari işlemler } \\
\text { dengesi arasında ters yönlü bir } \\
\text { ilişki bulunmuştur. }\end{array}$ \\
\hline $\begin{array}{l}\text { (Cesur \& İrez, } \\
\text { 2019) }\end{array}$ & $\begin{array}{l}\text { Etki-Tepki Analizi, } \\
\text { VAR analizi }\end{array}$ & 1990-2017 & Türkiye & $\begin{array}{l}\text { Ekonomik büyüme cari } \\
\text { dengeyi negatif yönde } \\
\text { etkilemektedir. }\end{array}$ \\
\hline (Uçak, 2017) & $\begin{array}{l}\text { Granger } \\
\text { nedensellik, VAR } \\
\text { modeli }\end{array}$ & $1980-2015$ & Türkiye & $\begin{array}{l}\text { Ekonomik büyümeden, cari } \\
\text { dengeye doğru } \\
\text { tek-yönlü bir nedensellik ilişki } \\
\text { bulunmuştur. }\end{array}$ \\
\hline $\begin{array}{l}\text { (Şit \& Alancioğlu, } \\
\text { 2016) }\end{array}$ & $\begin{array}{l}\text { Granger } \\
\text { nedensellik, VAR } \\
\text { modeli }\end{array}$ & $1980-2014$ & Türkiye & $\begin{array}{l}\text { Ekonomik büyüme ve cari } \\
\text { işlemler dengesi arasında çift } \\
\text { yönlü nedensellik ilişkisi tespit } \\
\text { edilmiştir }\end{array}$ \\
\hline (Koray, 2017) & $\begin{array}{l}\text { Granger } \\
\text { nedensellik, VAR } \\
\text { modeli }\end{array}$ & $2003-2017$ & Türkiye & $\begin{array}{l}\text { Ekonomik büyüme ile cari } \\
\text { işlemler dengesi arasında tek- } \\
\text { yönlü bir nedensellik ilişkisi } \\
\text { tespit edilmiştir. }\end{array}$ \\
\hline $\begin{array}{l}\text { (Bagnai \& } \\
\text { Manzocchi, 1999) }\end{array}$ & Panel-veri analiz & $1965-1994$ & $\begin{array}{l}49 \text { Gelişmekte } \\
\text { ülkeler }\end{array}$ & $\begin{array}{l}\text { Ekonomik büyüme artıkça cari } \\
\text { işlemler açığının artmasına } \\
\text { neden olmaktadır. }\end{array}$ \\
\hline (Erkılıç, 2006) & $\begin{array}{l}\text { EKK ve VAR } \\
\text { yöntemleri }\end{array}$ & $\begin{array}{l}1980-2005 \text { ve } \\
1987: 4-2005: 4\end{array}$ & Türkiye & $\begin{array}{l}\text { Ekonomik büyümenin } \\
\text { cari açığı arttırdığını } \\
\text { bulmuştur. }\end{array}$ \\
\hline $\begin{array}{l}\text { (Lebe, Kayhan, } \\
\text { Adı̈̈zel, \& Yiğit, } \\
\text { 2009) }\end{array}$ & $\begin{array}{l}\text { Gecikmeli yapısal } \\
\text { vektör oto } \\
\text { regresyon (SVAR) }\end{array}$ & $1997: 2-2007: 3$ & $\begin{array}{l}\text { Romanya ve } \\
\text { Türkiye }\end{array}$ & $\begin{array}{l}\text { Her iki ülkede de ekonomik } \\
\text { büyümedeki değişkenliğin } \\
\text { ulusal cari işlemler açı̆̆ının en } \\
\text { önemli nedeni olduğu sonucu } \\
\text { bulunmuştur. }\end{array}$ \\
\hline $\begin{array}{l}\text { (Yilmaz \& Akıncı, } \\
\text { 2011) }\end{array}$ & $\begin{array}{l}\text { Granger } \\
\text { nedensellik Eş- } \\
\text { bütünleşme Testi }\end{array}$ & $1980-2010$ & Türkiye & $\begin{array}{l}\text { GSYH'den cari işlemler } \\
\text { dengesine doğru tek yönlü bir } \\
\text { nedensellik ilişkisi } \\
\text { bulunmuştur. }\end{array}$ \\
\hline $\begin{array}{l}\text { (Hepaktan \& Çınar, } \\
\text { 2012) }\end{array}$ & Panel veri analizi & $1975-2008$ & 27 OECD ülke & $\begin{array}{l}\text { Ekonometrik uygulamaların } \\
\text { sonucunda ekonomik } \\
\text { büyümeden meydana gelen } \\
\text { 1'lik artış, cari işlemler } \\
\text { dengesinde } \%-0,2 \text { ve } \%-0,4 \\
\text { arasında azalışa yol açmaktadır. }\end{array}$ \\
\hline
\end{tabular}




\begin{tabular}{|c|c|c|c|c|}
\hline $\begin{array}{l}\text { (Songur \& Demet, } \\
2013 \text { ) }\end{array}$ & Panel veri analizi & $1981-2010$ & $\begin{array}{l}10 \text { Gelişmekte } \\
\text { olan ülke }\end{array}$ & $\begin{array}{l}\text { Uzun dönemde cari işlemler } \\
\text { dengesinden büyümeye doğru } \\
\text { pozitif ilişki varken büyümeden } \\
\text { cari işlemler dengesine doğru } \\
\text { negatif ilişki tespit edilmiştir. }\end{array}$ \\
\hline $\begin{array}{l}\text { (Yalçınkaya \& } \\
\text { Temelli, 2014) }\end{array}$ & Panel veri analizi & $1992-2013$ & $\begin{array}{l}\text { BRICS ve MINT } \\
\text { ülkeler }\end{array}$ & $\begin{array}{l}\text { İki grup ülkelerinde ekonomik } \\
\text { büyüme kısa ve uzun dönemde } \\
\text { cari işlemler dengesi üzerinde } \\
\text { önemli ölçüde etkili olduğu, } \\
\text { cari büyüme oranı değiştikçe } \\
\text { cari dengenin de ülkelere göre } \\
\text { açık-fazla verecektir. } \\
\text { Ekonomik büyümenin, cari } \\
\text { açığı artırıcı etkisinin } \\
\text { büyüklüğünün BRİCS } \\
\text { ülkelerine göre MINT } \\
\text { ülkelerinde daha önemli bir } \\
\text { sorun olduğu sonucuna } \\
\text { ulaşmıştır. }\end{array}$ \\
\hline $\begin{array}{l}\text { (Erdoğan \& Acet, } \\
\text { 2016) }\end{array}$ & $\begin{array}{l}\text { VAR analizi, } \\
\text { Varyans } \\
\text { Ayrıştırması, } \\
\text { Nedensellik Testi }\end{array}$ & 2003:01-2015:04 & Türkiye & $\begin{array}{l}\text { Ekonomik büyüme ile cari } \\
\text { denge arasında \%10 anlamlılık } \\
\text { düzeyinde çift yönlü bir } \\
\text { nedensellik ilişkisi } \\
\text { bulunmuşlardır. Varyans } \\
\text { ayrıştırmasına göre; cari } \\
\text { işlemler kendisinden \%84,6 } \\
\text { kaynaklarıyken \%15,4 ise } \\
\text { büyümeden } \\
\text { kaynaklanmaktadır, aynı } \\
\text { şekilde büyüme onuncu } \\
\text { döneminde \%87 kendisinden, } \\
\text { \%13'ü ise cari dengesinden } \\
\text { kaynaklanmaktadır. }\end{array}$ \\
\hline $\begin{array}{l}\text { (Ersungur, Doru, \& } \\
\text { Aslan, 2017) }\end{array}$ & $\begin{array}{l}\text { VAR modelli, } \\
\text { Nedensellik Testi }\end{array}$ & $1998-2014$ & Türkiye & $\begin{array}{l}\text { Cari denge ile GSYH arasında } \\
\text { iki taraflı bir nedensellik var } \\
\text { olduğu sonucuna ulaşmışlardır. } \\
\text { Ancak döviz kuru ve cari denge } \\
\text { arasında hiçbir ilişkiye } \\
\text { rastlanamamıştır. }\end{array}$ \\
\hline
\end{tabular}

\section{Veri Seti ve Metodoloji}

Bu çalışmada, Cari İşlemler Dengesi (CID) ile Gayri Safi Yurtiçi Hâsıla (GSYH) arasındaki ilişki E-views 10 paket programı kullanılarak araştırılmıştır. Bu seriler çalışmada sırasıyla Cari İşlemler Dengesi (CİD) Gayri Safi Yurtiçi Hâsıla (GSYH) olarak kısaltmıştır. Bu amaçla CID ve GSYH değişkenlerine ilişkin çeyrek zaman serileri (2005Q1-2019Q4) kullanılmıştır. Veriler Dünya Bankası ve Tacikistan Cumhuriyeti Merkez Bankası’ndan alınmıştır. Ekonomik büyüme ve CİD arasında kurulan model aşağıdaki gibidir.

Buna göre, ekonomik büyüme ile CİD arasında kurulan model,

$\mathrm{GSYH}=\beta+\beta_{1} \mathrm{CID}$ 
Tablo 4. Tanımlayıcı İstatistik

\begin{tabular}{|l|l|l|}
\hline & GSYH & CID \\
\hline Mean & 24.90583 & 13.02533 \\
\hline Median & 25.49000 & 10.31500 \\
\hline Maximum & 32.89000 & 46.01000 \\
\hline Minimum & 15.27000 & 0.300000 \\
\hline Std. Dev. & 5.648111 & 11.72803 \\
\hline Skewness & -0.269936 & 1.295947 \\
\hline Kurtosis & 1.590110 & 4.066424 \\
\hline & & \\
\hline Jarque-Bera & 5.698130 & 19.63794 \\
\hline Sum & 1494.350 & 781.5200 \\
\hline Sum Sq. Dev. & 1882.168 & 8115.259 \\
\hline & & \\
\hline Observations & 60 & 60 \\
\hline
\end{tabular}

Tablo 5. Kovaryans Analizi

Sample: 2005Q1 2019Q4

Included observations: 60

Correlation

Probability

Cases

Observations

GSYH

CID

GSYH

$\begin{array}{ll}1.000000 & \\ -60 & \\ 60 & \\ -0.492659 & 1.000000 \\ 0.0001 & -\cdots \\ 60 & 60 \\ 60 & 60\end{array}$

Kovaryans analizi sonucuna göre bu değişkenler arasında negatif bir ilişki vardır. Bağımlı değişkenli CID değeri \%50 olduğu için bu ilişkinin ılımlı olduğu anlamına gelmektedir.

\section{Tablo 6. Panel Birim Kök Test Sonuçları}

\begin{tabular}{|c|c|c|c|c|}
\hline \multicolumn{5}{|l|}{ Null Hypothesis: CID has a unit root } \\
\hline \multicolumn{5}{|l|}{ Exogenous: Constant } \\
\hline \multicolumn{5}{|c|}{ Lag Length: 3 (Automatic - based on SIC, maxlag=10) } \\
\hline & Level & & 1st Differen & \\
\hline & $\mathrm{t}$-Statistic & Prob.* & $\mathrm{t}$-Statistic & Prob.* \\
\hline Augmented Dickey-Fuller test statistic & -1.393454 & 0.5791 & -11.72465 & 0.0000 \\
\hline
\end{tabular}




\begin{tabular}{llll}
\hline $\begin{array}{l}\text { Test critical } \\
\text { values: }\end{array}$ & $1 \%$ level & -3.552666 & -3.552666 \\
\hline & $5 \%$ level & -2.914517 & -2.914517 \\
\hline & $10 \%$ level & -2.595033 & -2.595033 \\
\hline
\end{tabular}

*MacKinnon (1996) one-sided p-values.

Tablo 7. Panel Birim Kök Test Sonuçları

Null Hypothesis: GSYH has a unit root

Exogenous: Constant

Lag Length: 3 (Automatic - based on SIC, maxlag=10)

\begin{tabular}{llc}
\hline & t-Statistic & Prob.* $^{*}$ \\
\hline Augmented Dickey-Fuller test statistic & -3.665984 & 0.0073 \\
\hline
\end{tabular}

$\begin{array}{lll}\text { Test critical values: } \quad 1 \% \text { level } & -3.552666\end{array}$

\begin{tabular}{ll}
\hline $5 \%$ level & -2.914517 \\
\hline $10 \%$ level & -2.595033 \\
\hline
\end{tabular}

*MacKinnon (1996) one-sided p-values.

Değişkenler için verilerin durağan olup olmadığını belirttirmek amacıyla birim kök testi uygulandık. Bu testten elde edilen sonuçlarına göre bir değişkenimiz birinci farkta diğeri ise düzey değerinde durağın çıktı. Dolayısıyla biz bu değişkenler arasında uzun dönemde ilişkiyi bakmak için ARDL test uygulanacağız.

\section{Tablo 8. ARDL Test Sonuçları}

Dependent Variable: GSYH

Method: ARDL

Date: 06/22/20 Time: 17:45

Sample (adjusted): 2006Q1 2019Q4

Included observations: 56 after adjustments

Maximum dependent lags: 4 (Automatic selection)

Model selection method: Akaike info criterion (AIC)

Dynamic regressors (4 lags, automatic): CID

Fixed regressors: $\mathrm{C}$

Number of models evalulated: 20

Selected Model: $\operatorname{ARDL}(4,0)$ 


\begin{tabular}{|c|c|c|c|c|}
\hline Variable & Coefficient & Std. Error & $\mathrm{t}$-Statistic & Prob.* \\
\hline GSYH (-1) & -0.401553 & 0.116583 & -3.444367 & 0.0012 \\
\hline GSYH (-2) & -0.417261 & 0.117499 & -3.551197 & 0.0008 \\
\hline GSYH (-3) & -0.419651 & 0.115680 & -3.627678 & 0.0007 \\
\hline GSYH (-4) & 0.548989 & 0.119377 & 4.598792 & 0.0000 \\
\hline CID & -0.013632 & 0.014883 & -0.915966 & 0.3641 \\
\hline $\mathrm{C}$ & 42.24815 & 11.33086 & 3.728593 & 0.0005 \\
\hline R-squared & 0.966749 & \multicolumn{2}{|c|}{ Mean dependent var } & 24.90643 \\
\hline Adjusted R-squared & 0.963424 & \multicolumn{2}{|c|}{ S.D. dependent var } & 5.674778 \\
\hline S.E. of regression & 1.085294 & \multicolumn{2}{|c|}{ Akaike info criterion } & 3.102536 \\
\hline Sum squared resid & 58.89315 & \multicolumn{2}{|c|}{ Schwarz criterion } & 3.319538 \\
\hline Log likelihood & -80.87100 & \multicolumn{2}{|c|}{ Hannan-Quinn criter. } & 3.186667 \\
\hline F-statistic & 290.7430 & \multicolumn{2}{|c|}{ Durbin-Watson stat } & 1.775642 \\
\hline Prob(F-statistic) & 0.000000 & & & \\
\hline
\end{tabular}

*Note: p-values and any subsequent tests do not account for model selection.

Yukarıda Tablo 17'de ARDL test sonuçları verilmektedir. Bu sonuçlara göre değişkenler arasında oto korelasyon yoktur ve $\mathrm{F}$ istatistiği problemi de görülmemektedir. Bu sebeple değişkenler arasında uzun donem ilişki olup olmadığını tespit etmek amacıyla ARDL sınır testi yapmamız gerekmektedir.

Tablo 9. ARDL Sınır Testi

F-Bounds Test

Null Hypothesis: No levels relationship

\begin{tabular}{llllr}
\hline \hline Test Statistic & Value & Signif. & I(0) & I(1) \\
\hline \hline & & & \multicolumn{2}{c}{ Asymptotic: $\mathrm{n}=1000$} \\
F-statistic & 4.86608 & $10 \%$ & 3.02 & 3.51 \\
K & 1 & $5 \%$ & 3.62 & 4.16 \\
& & $2.5 \%$ & 4.18 & 4.79 \\
& & $1 \%$ & 4.94 & 5.58
\end{tabular}

Yukarıdaki tabloda ARDL sınır testi sonuçlarına sahibiz. Bu test sonuçlarına göre F-istatistiği değeri üst sınırdan daha büyük olduğundan değişkenler arasında uzun dönemli bir ilişki olduğunu söyleyebiliriz. 


\section{Tablo 10. Correlogram}

Included observations: 56

Q-statistic probabilities adjusted for 4 dynamic regressors

\begin{tabular}{|c|c|c|c|c|c|c|}
\hline Autocorrelation & Partial Correlation & & $\mathrm{AC}$ & PAC & Q-Stat & Prob* \\
\hline$\left.\cdot\right|^{*} . \quad \mid$ &.$\left.\right|^{*}$ & 1 & 0.097 & 0.097 & 0.5580 & 0.455 \\
\hline$.\left.\right|^{*} . \quad \mid$ & $.\left.\right|^{*} . \quad \mid$ & 2 & 0.096 & 0.088 & 1.1147 & 0.573 \\
\hline${ }^{* *}|. \quad|$ & $* *|. \quad|$ & 3 & -0.219 & -0.240 & 4.0609 & 0.255 \\
\hline$* *|. \quad|$ & $* *|. \quad|$ & 4 & -0.236 & -0.215 & 7.5321 & 0.110 \\
\hline.$|\cdot|$ & $.\left.\right|^{*} \cdot \mid$ & 5 & 0.069 & 0.173 & 7.8318 & 0.166 \\
\hline.$|\cdot|$ &.$|\cdot|$ & 6 & 0.005 & -0.011 & 7.8335 & 0.251 \\
\hline.$|\cdot|$ & $.^{*} \cdot \mid$ & 7 & 0.041 & -0.108 & 7.9468 & 0.337 \\
\hline.$*||$. & $.{ }^{*} \cdot \mid$ & 8 & -0.148 & -0.167 & 9.4358 & 0.307 \\
\hline.$*||$. & $.^{*} \cdot \mid$ & 9 & -0.187 & -0.116 & 11.864 & 0.221 \\
\hline.$|\cdot|$ &.$|\cdot|$ & 10 & -0.034 & 0.023 & 11.943 & 0.289 \\
\hline$\cdot{ }^{*} \cdot \mid$ & $\cdot{ }^{*} \cdot \mid$ & 11 & -0.066 & -0.119 & 12.261 & 0.344 \\
\hline.$||$. &.$*||$. & 12 & -0.015 & -0.186 & 12.278 & 0.424 \\
\hline.$|\cdot|$ &.$|\cdot|$ & 13 & 0.028 & 0.013 & 12.338 & 0.500 \\
\hline.$*||$. &.$*||$. & 14 & -0.076 & -0.076 & 12.781 & 0.544 \\
\hline.$|\cdot|$ &.$|\cdot|$ & 15 & 0.045 & -0.056 & 12.943 & 0.607 \\
\hline$.^{*} \mid$ & **|. | & 16 & -0.131 & -0.231 & 14.333 & 0.574 \\
\hline$.\left.\right|^{*} . \quad \mid$ &.$|\cdot|$ & 17 & 0.112 & 0.059 & 15.373 & 0.569 \\
\hline.$||$. & $.^{*} \cdot \mid$ & 18 & -0.033 & -0.087 & 15.466 & 0.630 \\
\hline.$|\cdot|$ &.$*|. \quad|$ & 19 & 0.056 & -0.088 & 15.741 & 0.674 \\
\hline.$|\cdot|$ & $.^{*} \cdot \mid$ & 20 & 0.023 & -0.126 & 15.789 & 0.730 \\
\hline.$|\cdot|$ &.$||$. & 21 & -0.025 & -0.040 & 15.845 & 0.778 \\
\hline.$||$. &.$|\cdot|$ & 22 & 0.043 & -0.041 & 16.025 & 0.815 \\
\hline.$|\cdot|$ &.$|\cdot|$ & 23 & 0.034 & -0.039 & 16.138 & 0.849 \\
\hline$.\left.\right|^{* *} \mid$ & $\left.\cdot\right|^{*} \cdot \mid$ & 24 & 0.223 & 0.148 & 21.170 & 0.629 \\
\hline
\end{tabular}

Yukarıda tablo 19'de elde ettiğimiz sonuçlarına göre, tüm durumlarda P değeri yüzde beşin üzerinde olduğundan dolayı oto korelasyon yoktur. 


\section{Grafik 2. Histogram Normallik Testi}

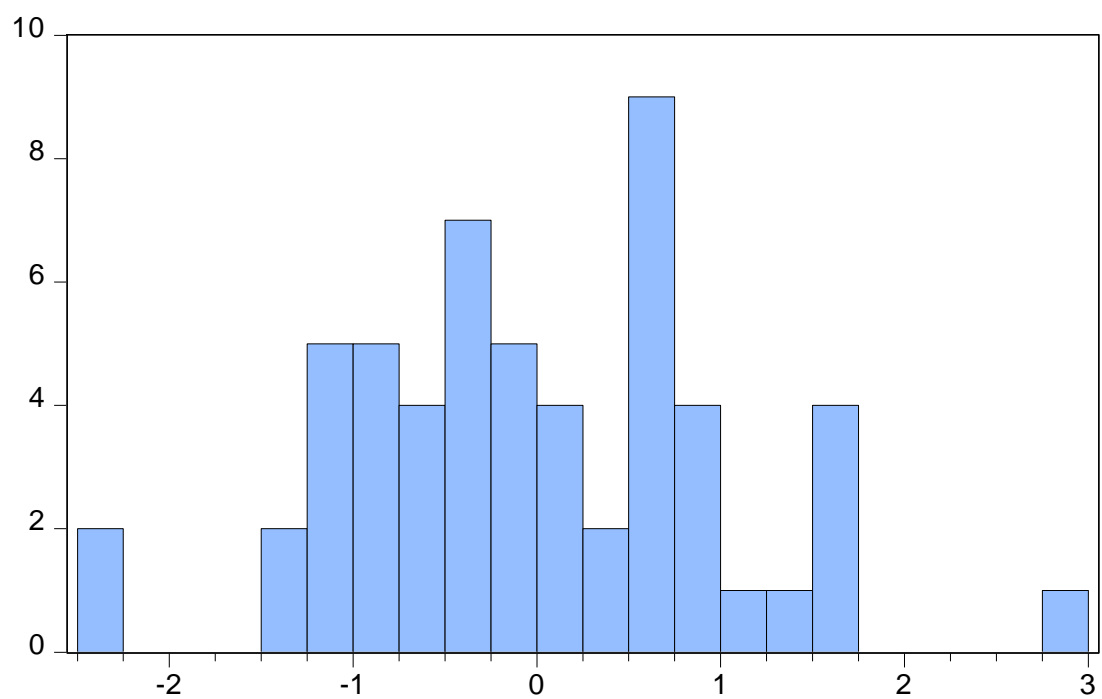

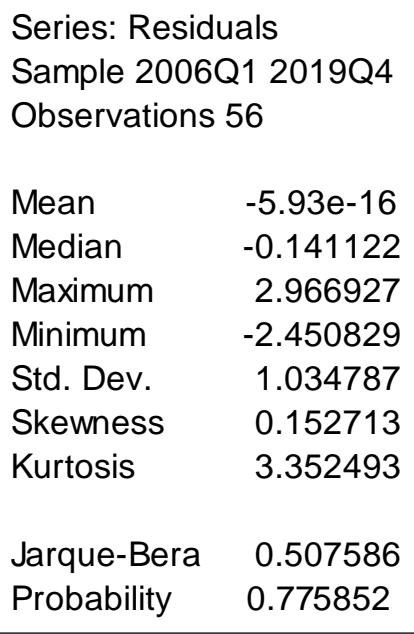

Yukarıdaki grafikte, histogram normalik test sonuçlarına göre p değerinin $\% 5^{\prime}$ inde sıfır hipotezini reddeden $\% 5^{\prime}$ ten fazla olduğu için modelimizin normal olduğunu söylemektedir.

\section{Tablo 11. ARCH test sonuçları}

Heteroskedasticity Test: ARCH

\begin{tabular}{llll}
\hline \hline F-statistic & 0.197253 & Prob. F(1,53) & 0.6588 \\
Obs*R-squared & 0.203937 & Prob. Chi-Square(1) & 0.6516
\end{tabular}

P değeri \%10'dan fazla olduğu için heteroskedastisite problemi olmadığı anlamına gelmektedir.

\section{Sonuç ve Değerlendirme}

Tacikistan ekonomisinde özellikle son dönemlerde cari açığın milli gelire oranı oldukça yüksektir. Cari işlemler dengesi ile diğer makroekonomik göstergeler arasındaki ilişkiler, ekonomik politika kararları açısından cari işlemler dengesini hangi faktörlerin ne ölçüde etkilediğini araştırmayı önemli kılmaktadır. Bu çalışmada, Tacikistan Cumhuriyetinin cari işlemler dengesi ve ekonomik büyüme arasındaki ilişkiyi tespit etmek amacıyla 2005Q1 ve 2019Q4 arasındaki döneme ilişkin veriler değerlendirilerek ARDL yöntemi kullanılarak analiz edilmiştir. Analiz sonucunda elde edilen sonuçlar aşağıdaki gibi özetlenmektedir. İlk değişkenlerimizin durağın olup olmadığını belirttirmek amacıyla Birim kök testi uygulanmıştır. Analiz sonucunda bir değişken birinci farkta, diğeri ise düzey değerinde durağan çıktı. Dolayısıyla ARDL modeli kullanıldı. Elde edilen sonuçlarına göre değişkenler arsında negatif bir ilişki vardır. Aynı zamanda uzun dönem ilişki olup olmadığını tespit etmek amacıyla ARDL sınır testi uygulanmıştır.

Yukarıdaki ampirik sonuçlarda da görüldüğü gibi değişkenler arasında negatif bir ilişki bulunmaktadır. Bilindiği üzere cari işlemler dengesi, ticaret politikası, döviz kuru, döviz rezervleri, enflasyon oranı gibi çeşitli faktörlerden etkilenmektedir. Dış ticaret dengesi, genellikle cari işlemler fazlası veya açığının en büyük belirleyicisidir. Tacikistan'da dış ticaret genellikle açık vermektedir. Tacikistan için cari açığının en büyük sebebi dış ticaret açığıdır. Tablo 6'daki dış ticaret verilerine bakıldığında; Tacikistan 2018 yılında 11 milyar dolarlık mal ve hizmet ihraç ederken 32 milyar dolarlık mal ve hizmet ithal etmiştir. Mal ve hizmetler dengesi ise -21 milyar dolar olmuştur. Tacikistan'ın ihracatındaki başlıca ürünler Alüminyum, Kurşun cevheri, Altın, Pamuk, Çinko cevheri, diğer metal cevherler yer almaktadır. Yani Tacikistan en çok hammadde ihraç 
etmektedir. Sonuç olarak Tacikistan hammadde bağımlılığından kurtulmazsa cari işlemler dengesi açı̆̆ı giderek artabilir ve gelirlerle finanse edilemediği müddetçe kronik hale gelebilecektir.

\section{Kaynakça}

Aahana, S. (2020). Structure of Balance of Payments Accounts | International Trade | Economics. Economics Discussion: Erişim Tarihi: 01.05.2020, http://www.economicsdiscussion.net/balance-of-payment/structure-of-balance-ofpayments-accounts-international-trade-economics/30647 adresinden alındı

Bagnai, A., \& Manzocchi, S. (1999). Current-Account Reversals in Developing Countries: The Role of Fundamentals. Open economies review 10, 143-163.

Cesur, F., \& İrez, S. (2019). Cari Açığın Ekonomik Büyüme Üzerindeki Etkisi: Türkiye Örneği. Sosyal Araştırmalar ve Davranış Bilimleri Dergisi Cilt 5, Sayı8,, 87-101.

Dünya Bankası. (2019). Erişim Tarihi: 20.01.2020, https://data.worldbank.org/ adresinden alındı

Erdoğan, S., \& Acet, H. (2016). Cari İşlemler Dengesi ve Ekonomik Büyüme Arasındaki İlişki: Türkiye Örneği (20032015). The Journal of Academic Social Science Studies Number: 51(3), 539-548.

Erkılıç, S. (2006). Tüerkiye'de Cari Açı̆̆ın Velirleyecileri. Türkiye Cumhuriyet Merkez Bankası İstatistik Genel Müdürlüğü, Uzmanlık Yeterlilik Tezi, 1-152.

Ershov, Y. S., \& Sadriddinov, M. İ. (2016). Ekonomika Tajikistana v XXI Veke- Vzglyad so Storonı. Mir ekonomiki i upravleniya, 125-135.

Ersungur, M., Doru, Ö., \& Aslan, B. (2017). Türkiye’de GSYH ve Döviz Kuru Hareketlerinin Cari Denge Üzerindeki Etkisi: VAR Analizi Yaklaşimi. Atatürk Üniversitesi İktisadi ve İdari Bilimler Cilt 31(3), 451-462.

Ghosh, A., \& Ramakrishnan, U. (2020). Current Account Deficits: Is There a Problem? İnternational Monetary Fund: Erişim Tarihi: 02.05.2020, https://www.imf.org/external/pubs/ft/fandd/basics/current.htm adresinden alındı

Heakal, R. (2019). Current Account Balance. Investopedia: Erişim Tarihi: 20.04.2020, https://www.investopedia.com/insights/exploring-current-account-in-balance-of-payments/ adresinden alındı

Hepaktan, E., \& Çınar, S. (2012). OECD Ülkelerinde Büyüme-Cari İşlemler Dengesi İlişkisi: Panel Veri Analizi. Anadolu Üniversitesi Sosyal Bilimler Dergisi, 43-57.

Kimberly, A. (2019). Economic Growth, Its Measurements, Causes, and Effects. The balance: Erişim Tarihi: 02.05.2020, https://www.thebalance.com/what-is-economic-growth-3306014 adresinden alındı

Koray, Y. D. (2017). Türkiye'de Cari İşlemler Dengesi ve Ekonomik Büyüme Arasındaki İlişki. Sakarya İktisat Dergisi, Cilt 6, Sayı 4, 12-28.

Lebe, F., Kayhan, S., Adıgüzel, U., \& Yiğit, B. (2009). The Empirical Analysis Of The Effects Of Economic Growth And Exchange Rate On Current Account Deficit: Romania And Turkey Samples. Journal of applied quantitative methods Vol. 4(1), 69-81.

$\begin{array}{lllll}\text { ScienceDaily. } & \text { (2020). Economic } & \text { growth. } & \text { Erişim } & \text { Tarihi: 2020, }\end{array}$ https://www.sciencedaily.com/terms/economic_growth.htm adresinden alındı

Songur, M., \& Demet, D. (2013). Gelişmekte Olan Ülkelerde Cari İşlemler Dengesi ve Ekonomik Büyüme Arasındaki İlişki: Panel Veri Analizi. Maliye Dergisi Sayı 164, 220-232.

Şit, M., \& Alancıoğlu, E. (2016). Türkiye’de Cari İşlemler Dengesi ve Ekonomik Büyümearasındaki İlişki: Var Analizi. ASSAM Uluslararası Hakemli Dergi, Sayı 5, 5-23.

TCMB. (2020). Ödemeler Dengesi İstatistikleri. Ankara: Türkiye Cumhuriyet Merkez Bankası.

Telatar, M. O., \& Terzi, H. (2009). Türkiye'de Ekonomik Büyüme ve Cari İşlemler Dengesi İlişkisi. Atatürk Üniversitesi İktisadi ve İdari Bilimler Dergis Cilt: 23, Sayı: 2, 119-134. 
The World Bank. (2020). GDP growth (annual \%). Erişim Tarihi: 18.04.2020, https://data.worldbank.org/indicator/NY.GDP.MKTP.KD.ZG adresinden alındı

Uçak, S. (2017). Cari Denge ve Ekonomik Büyüme İlişkisi: Türkiye Analizi. MCBÜ Sosyal Bilimler Dergisi Cilt:15, Sayı:2, $107-140$.

Yalçınkaya, Ö., \& Temelli, F. (2014). Ekonomik Büyüme ile Cari İşlemler Dengesi Arasındaki İlişki: BRICS ve MINT (1992-2013). Süleyman Demirel Üniversitesi İ̈BF dergisi Cilt 19(4), 201-224.

Yılmaz, Ö., \& Akıncı, M. (2011). İktisadi Büyüme ile Cari İşlemler Bilançosu Arasındaki İlişki: Türkiye Örneği. Atatürk Üniversitesi Sosyal Bilimler Enstitüsü Dergisi 15 (2), 363-377. 